Shock-tube water time-histories and ignition delay time measurements for $\mathrm{H}_{2} \mathrm{~S}$ near atmospheric pressure

Olivier Mathieu, Clayton Mulvihill, and Eric L. Petersen

Department of Mechanical Engineering, Texas A\&M University, College Station, TX 77843, USA

Corresponding author:

Olivier Mathieu

Department of Mechanical Engineering,

Texas A\&M University

College Station

Texas 77843

USA

Phone: +1 (979) 845-7429

Fax: +1 (979) 845-3081

Email: olivier.mathieu@tamu.edu

Total length of paper: 6135 words (Method 1)

- Main text: 3820 words (word processor utility)

- References: $(20$ references +2$)$ x $2.3 \times 7.6=384$ words

- Figures and captions: Tab. 1: $(10+2) \times 7.6 \times 2=182$ words

Fig. 1: $(47.8+10) \times 2.2 \times 1+9=136$ words

Fig. $2:(122.4+10) \times 2.2 \times 2+29=612$ words

Fig. 3: $(140+10) \times 2.2 \times 2+18=678$ words

Fig. $4:(53.3+10) \times 2.2 \times 1+24=163$ words

Fig. $5:(53.3+10) \times 2.2 \times 1+20=159$ words

This paper has Supplemental Material

4 Figures with colored lines can be reproduced in grayscale as needed 
Abstract

Hydrogen sulfide combustion has been of interest in recent years due to its presence in coal-derived syngas and in sour gas. However, there are limited data available for the calibration of chemical kinetics models of high-temperature $\mathrm{H}_{2} \mathrm{~S}$ oxidation. Ignition delay times and laserabsorption water time histories were therefore measured in two different shock tubes around atmospheric pressure over a range of temperatures from 1445 to $2210 \mathrm{~K}$ for $\mathrm{H}_{2} \mathrm{~S}-\mathrm{O}_{2}$ mixtures diluted in $98 \%$ Ar. While modern $\mathrm{H}_{2} \mathrm{~S}$ models from the literature predicted the ignition delay times with fair accuracy, the water profiles were initially very poorly predicted with the same kinetic mechanisms. A model analysis showed that the reaction $\mathrm{R} 62$, $\mathrm{SH}+\mathrm{HO}_{2} \leftrightarrows \mathrm{H}_{2} \mathrm{~S}+\mathrm{O}_{2}$ (in reverse), was chiefly responsible for these poor predictions. It was possible to obtain better water predictions when the rate for R62 was divided by 10. A tentative model is proposed herein, based on this assumption for R62, and good predictions were obtained for both the ignition delay times and water profiles, as well as for former high-pressure shock-tube data with $\mathrm{H}_{2}-\mathrm{H}_{2} \mathrm{~S}$ mixtures. The present study shows that more accurate rates for the reactions $\mathrm{R} 62\left(\mathrm{SH}+\mathrm{HO}_{2} \leftrightarrows \mathrm{H}_{2} \mathrm{~S}+\right.$ $\left.\mathrm{O}_{2}\right), \mathrm{R} 75\left(\mathrm{SH}+\mathrm{O}_{2} \leftrightarrows \mathrm{HSO}+\mathrm{O}\right)$, and $\mathrm{R} 46(\mathrm{SH}+\mathrm{SH}(+\mathrm{M}) \leftrightarrows \mathrm{HSSH}(+\mathrm{M}))$ would be needed to better predict $\mathrm{H}_{2} \mathrm{~S}$ combustion chemistry.

Keywords: shock tube, $\mathrm{H}_{2} \mathrm{~S}$, ignition delay time, water, laser absorption 
1. Introduction

Hydrogen sulfide $\left(\mathrm{H}_{2} \mathrm{~S}\right)$ is an important and regulated by-product of the oil industry and also a constituent (up to $30 \%$ by vol.) of a large fraction of natural gas resources (so-called sour natural gas) [1]. Syngas blends produced from either coal or biomass can also contain $\mathrm{H}_{2} \mathrm{~S}$, up to $1.3 \% \mathrm{~mol}[2]$, and it has been shown that $\mathrm{H}_{2} \mathrm{~S}$, even in small proportion, can have a noticeable effect on important combustion properties such as ignition delay time $\left(\tau_{\text {ign }}\right)[2,3]$ and flame speed [4] for hydrogen-based mixtures. For these reasons, $\mathrm{H}_{2} \mathrm{~S}$ combustion chemistry has been the topic of several recent studies [1,3,5-9].

However, despite these recent studies, the combustion chemistry of $\mathrm{H}_{2} \mathrm{~S}$ is still not very well understood. This lack of understanding is due to both the very limited amount of experimental data available to validate the models and to the presence of many sensitive reactions with a relatively high uncertainty in the models $[1,3,7]$. In addition, some of the few experimental data available seem to suffer from large uncertainties. For instance, a difference as large as 20 $\mathrm{cm} / \mathrm{s}$ can be observed between laminar burning velocity studies of $\mathrm{H}_{2} \mathrm{~S}$ at stoichiometric, room conditions [1]. The effects of surface reactions in quartz flow reactors are also unclear and, even with surface coating to prevent catalytic reactions, Zhou et al. [7] were not able to model all of their experiments without changing a few reaction rates from one condition to the other.

The model from Zhou et al. [7], owing to its larger number of species/reactions and to the fact that numerous important reactions have been determined by high-level calculation, has been recently used as a foundation for several studies aiming to improve $\mathrm{H}_{2} \mathrm{~S}$ combustion chemistry $[1,3,9]$. Mathieu et al. [3] measured ignition delay times of diluted mixtures of $\mathrm{H}_{2} / \mathrm{O}_{2}$ seeded with various amount of $\mathrm{H}_{2} \mathrm{~S}$ between 1.5 and 35 atm. Using their data as a support, they changed a few reaction rates from the Zhou et al. mechanism within their uncertainties and were able to reproduce their ignition delay time data and some other data from the literature. 
However, they failed to reproduce the flow reactor data from Zhou et al. [7]. More recently, Bongartz and Ghoniem [1] also started from the Zhou et al. mechanism and tried to optimize $\mathrm{H}_{2} \mathrm{~S}$ chemistry by using several targets, including laminar burning velocities and flow reactor results from Zhou et al. [7]. They identified that it was necessary to change the rates of 15 reactions within their uncertainties; good agreement was found between the model and the data when optimizing against laminar burning velocity, ignition delay time, and pyrolysis data ("Optimization 1-7" in their paper) or for the flow reactor data of Zhou and coworkers. Larger discrepancies were observed for a combination of all these data as targets (“Optimization 1-12"). They also observed that the rates of several important reactions were changed in opposite directions in the optimization method, depending on which targets were used. They concluded that more accurate direct determinations of the rate constant were needed for these important reactions, without pointing at a particular reaction.

The present study was initiated to improve $\mathrm{H}_{2} \mathrm{~S}$ combustion chemistry by presenting new ignition delay time $\left(\tau_{\text {ign }}\right)$ and water time-history profiles in shock tubes for $\mathrm{H}_{2} \mathrm{~S} / \mathrm{O}_{2}$ mixtures in $98 \% \mathrm{Ar}$ around atmospheric pressure and for 3 equivalence ratios $(\phi): 0.5,1.0$, and 1.5. Using these results as a guide, a tentative $\mathrm{H}_{2} \mathrm{~S}$ kinetics mechanism is proposed herein. Details on the experimental procedure are covered first, followed by the experimental results and the model's improvements and validation stages.

\section{Experimental apparatuses}

Laser absorption and ignition delay time experiments were conducted in two different shock tubes. Although the dimensions of these facilities are slightly different, they share some similarities, described below. Both tubes are single-diaphragm, made of stainless-steel, with a 7.62-cm i.d. driver section (2.46-m long for the ignition delay time tube (IST); 3-m long for the 
water diagnostic tube (DST)) with a large-diameter driven section (15.24-cm i.d., 4.72-m long for the IST; 16.2-cm i.d., 6.78-m long for the DST). In both cases, PCB P113A piezoelectric pressure transducers were used along the driven section to measure the incident-wave velocities. A curve fit of the measured velocities was used to determine the incident wave speed at the endwall location. Post reflected-shock conditions were obtained using this extrapolated wave speed in conjunction with the one-dimensional shock relations and the initial conditions in the test region. This method was proven to maintain the uncertainty in the temperature determination behind reflected shock waves $\left(T_{5}\right)$ below $10 \mathrm{~K}$ as described in Petersen et al. [10]. Test pressure was monitored by a Kistler 603 B1 transducer located at the sidewall, in the same plane as the observation windows (sapphire, $16 \mathrm{~mm}$ from the endwall). Non-ideal boundary layer effects measured by the change in pressure $(d \mathrm{P} / d \mathrm{t})$ behind the reflected shock wave were determined to be less than $2 \% / \mathrm{ms}$ in each facility. Polycarbonate diaphragms $(0.25-\mathrm{mm}$ thickness) were used, and a cross-shaped cutter was employed to facilitate their breakage and prevent fragments from tearing off. The driven sections were vacuumed down to $2 \times 10^{-5}$ Torr or better prior to every run. The pumping time between experiments was minimized using a pneumatically driven poppet valve matching the inside diameter of the driven section for each tube. Test mixtures were prepared manometrically in a stainless steel mixing tank shared by the two facilities.

The gases, $\mathrm{O}_{2}$, Ar (both $99.999 \%$ purity), and $\mathrm{H}_{2} \mathrm{~S}\left(1.01 \% \mathrm{H}_{2} \mathrm{~S}(99.9 \%\right.$ purity) diluted in $\operatorname{Ar}(99.999 \%)$ by Praxair) were passed through a perforated tube traversing the center of the mixing vessel to allow for rapid, turbulent mixing. The conditions investigated and experimental results $\left(\tau_{\text {ign }}\right.$ and water profiles, along with corresponding pressure and temperature conditions behind the reflected shock waves (RSW)) are provided as supplementary material. 


\subsection{Ignition delay time shock tube}

Ignition delay time was defined as the time between the passage of the RSW and the intersection of lines drawn along the steepest rate-of-change of $\mathrm{OH}^{*}$ de-excitation (i.e., chemiluminescence) and a horizontal line which defines the zero-concentration level, as documented in Mathieu et al. [3] (an example is also provided as supplementary material). The emission spectroscopy from the $\mathrm{A}^{2} \Sigma^{+} \rightarrow \mathrm{X}^{2} \Pi$ transition of the excited-state hydroxyl radical $\left(\mathrm{OH}^{*}\right)$ was followed at the sidewall location using an interference filter centered at $307 \pm 10 \mathrm{~nm}$ with a Hamamatsu 1P21 photomultiplier tube in a custom-made housing. Some representative $\mathrm{OH}^{*}$ profiles are provided as supplementary material.

Uncertainties in the ignition delay time are primarily due to the uncertainty in $\mathrm{T}_{5}$ determination (below $10 \mathrm{~K}$, as discussed above). As a result, the uncertainty in $\tau_{\mathrm{ign}}$ reported in this study is around $10 \%$. This uncertainty level takes into account the non-ideal boundary layer effects measured by the change in pressure $(d \mathrm{P} / d \mathrm{t})$ behind RSW.

\subsection{Water diagnostic shock tube}

A tunable diode laser (Toptica Photonics DL100L) generated laser light near $1388.14 \mathrm{~nm}$. The wavelength of the laser was controlled by a temperature and current controller (Toptica Photonics DC110) and was monitored by a Burleigh WA-1000 wavemeter. Typical operating conditions for the laser were $20.0^{\circ} \mathrm{C}$ and $98 \mathrm{~mA}$. The incident $\left(\mathrm{I}_{0}\right)$ and transmitted (I) laser intensities were measured using a pair of Newport 2317NF photodetectors, allowing for the transient water concentration within the shock tube to be calculated using the Beer-Lambert relation, $\mathrm{I} / \mathrm{I}_{0}=\exp \left(-k_{v} \mathrm{P}_{\text {abs }} \mathrm{L}\right)$ (with $k_{v}$ the absorption coefficient $\left(\mathrm{cm}^{-1} \mathrm{~atm}^{-1}\right), \mathrm{P}_{\text {abs }}$ the partial pressure of water $(\mathrm{atm})$, and $\mathrm{L}$ the path length $(16.2 \mathrm{~cm}))$. A schematic of the optical set-up is visible in 
Fig. 1. The detector signals were sampled at $1 \mathrm{MHz}$ using common-mode rejection through a low-noise differential preamplifier (Stanford Research Systems model 560). Both detectors were fitted with a bandpass filter centered at $1384 \mathrm{~nm}$ with a full width at half maximum of $10 \mathrm{~nm}$. The measured portion of the laser beam path was purged with $\mathrm{N}_{2}$.

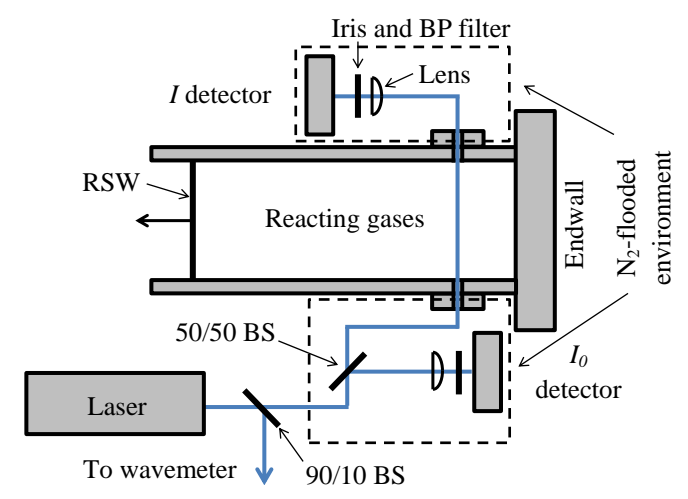

Figure 1: Schematic of the laser diagnostic used during this study.

The exothermicity of the reactions taking place in these experiments causes a significant temperature rise over the 2-3 milliseconds of test time (typically 200-300 K). A correction was therefore applied to the absorption coefficient for each measurement since $k_{v}$ is a strong function of temperature: $\left(k_{\nu}=S(T) \phi\left(\bar{v}-\bar{v}_{0}\right)\right)$. The linestrength $S(T)$ is obtained from the HITRAN spectroscopic database [11]. The lineshape $\phi\left(\bar{v}-\bar{v}_{0}\right)$ is given by the Voigt profile, as approximated by the expression from Whiting [12]. The Voigt profile is the convolution of Doppler and collisional broadening effects. These broadening effects are functions of temperature and species concentrations. The simulated temperature rise was used to calculate a transient absorption coefficient profile, which was then applied to the raw data to obtain a water time-history. The time-history was scaled to match the model as the amount of water approached the equilibrium value for the given mixture. Changes to the model were made as suggested by discrepancies between the model and data, allowing for a slightly different simulated temperature rise. The new 
temperature profile was then applied to the raw data yet again; the final mechanism was obtained by iterating on this procedure. The detection level ranged from 0.9 to $1.9 \%$ absorption, and the estimated accuracy on water concentration is between 1.25 and $6.25 \%$. The dilution level used herein $(98 \%$ Ar) was selected to have a good balance between the detection level and the exothermicity.

3. Experimental results

\subsection{Ignition delay time}

The ignition delay times measured during this study are visible in Fig. 2 (a) for the three equivalence ratios investigated. As can be seen, the ignition delay time increases with the equivalence ratio. This increase in $\tau_{\text {ign }}$ is also associated with a slight increase in the activation energy, leading to a larger increase in $\tau_{\text {ign }}$ on the low-temperature side (increase in $\tau_{\text {ign }}$ by a factor close to 2 between $\phi=0.5$ and 1.5) than for the high-temperature side (increase in $\tau_{\text {ign }}$ by around $40 \%$ between $\phi=0.5$ and 1.5). Note that the difference in $\tau_{\text {ign }}$ is larger between $\phi=0.5$ and 1.0 (between 22 (high temperature) and 39\% (low temperature)) than between $\phi=1.0$ and 1.5 (between 18 (high temperature) and 27\% (low temperature)). Finally, one can also notice a slight curvature in the data, for all conditions investigated. 


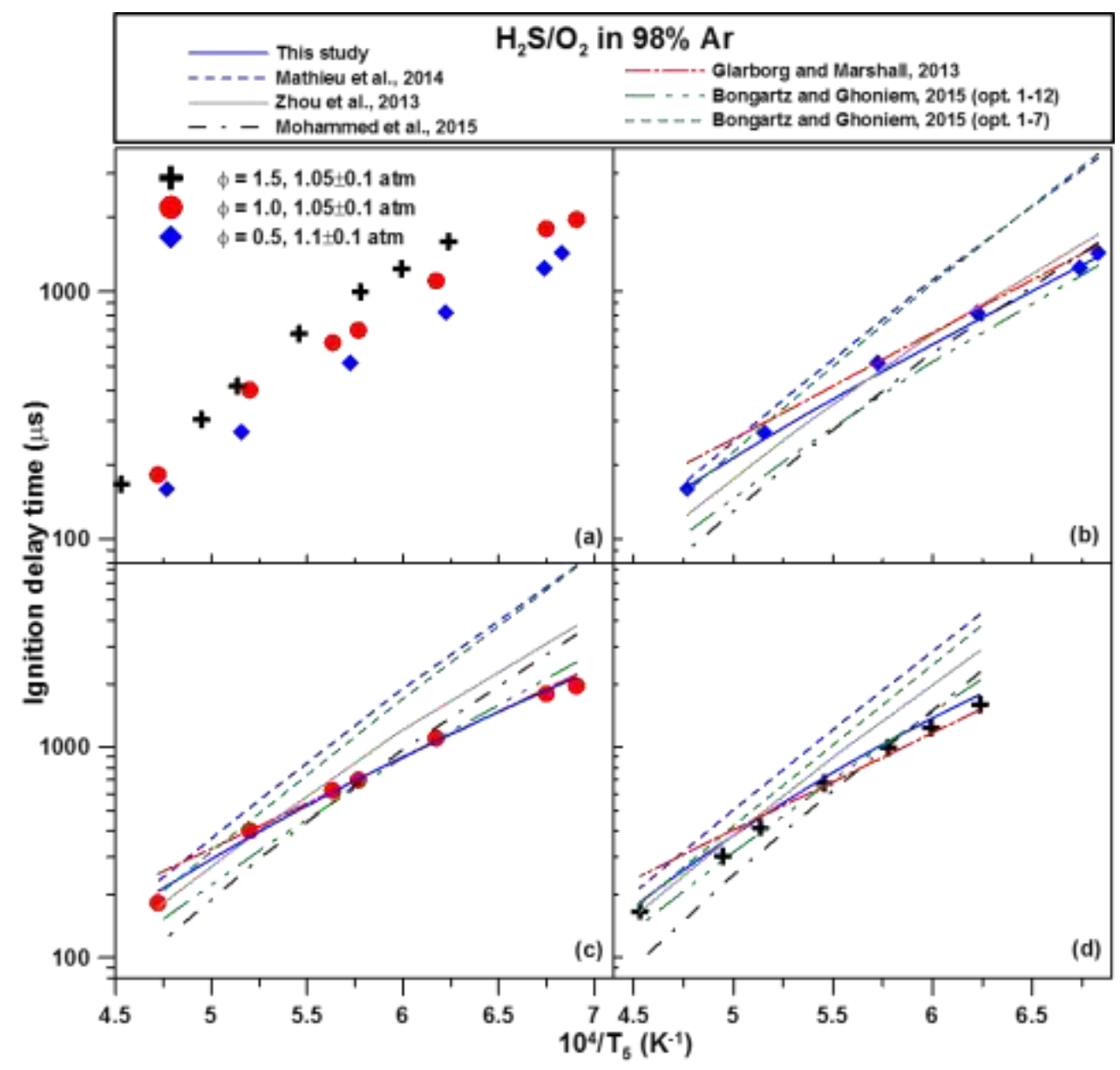

Figure 2: Ignition delay time measurements for $\mathrm{H}_{2} \mathrm{~S} / \mathrm{O}_{2}$ mixtures in $98 \% \mathrm{Ar}$ (a) and comparison with models at $\phi=0.5(\mathrm{~b}), \phi=1.0(\mathrm{c})$, and $\phi=1.5(\mathrm{~d})$.

\subsection{Water concentration time-histories}

Representative examples of the water profiles measured during this study are visible in Fig. 3 for $\phi=0.5$ (a, d, g), 1.0 (b, e, h), and 1.5 (c, f, i). All other water profiles measured are available as supplementary material. For each equivalence ratio, an example at low (top), intermediate (middle), and high temperature (bottom) is presented. As can be seen, the formation of water starts after a delay that decreases as the temperature increases. The water concentration then increases rapidly, around a time corresponding to the ignition delay time, before approaching a plateau. Some differences can however be observed between the three equivalence ratios 
investigated. One can notably see that after the growth period, the transition to the plateau is relatively rapid at $\phi=0.5$ compared to the stoichiometric case, where the transition is smoother. At fuel rich conditions, it is visible that the water reaches a peak right after the growth period, and then the concentration decreases rapidly until the plateau level is reached. Finally, the slope of the growth period also decreases as $\phi$ increases.

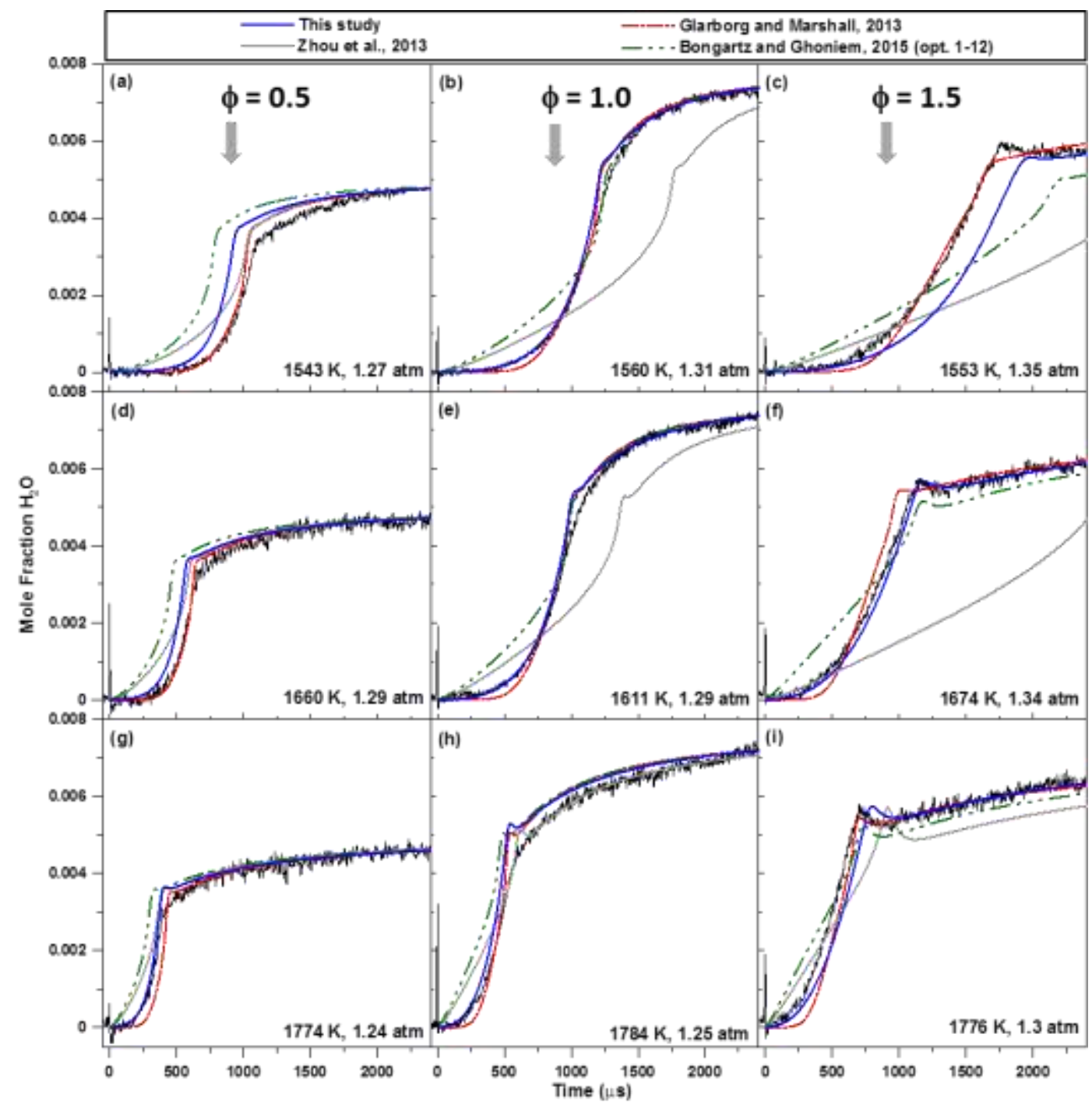

Figure 3: Evolution with equivalence ratio and temperature of water time-histories during the oxidation of $\mathrm{H}_{2} \mathrm{~S} / \mathrm{O}_{2}$ mixtures in $98 \%$ Ar. 


\section{Chemical kinetics modeling}

A tentative model for $\mathrm{H}_{2} \mathrm{~S}$ combustion is proposed in this study. This model is based on the model of Zhou et al. [7] and was modified in light of the experimental results from the present study. Modifications from the original model of Zhou et al. are the following: first, the $\mathrm{H}_{2} / \mathrm{O}_{2}$ chemistry was updated with the sub-mechanism from Kéromnès et al. [13], and the $\mathrm{OH}^{*}$ chemistry from Hall and Petersen [14] was added to model $\tau_{\mathrm{ign} .}$. The thermodynamic data were updated using the work of Goos et al. [15], notably for the radicals SH (following the recommendation from Bongartz and Ghoniem [1]), and $\mathrm{HSOO}(\mathrm{Cp} / \mathrm{R}$ decreases when the temperature increases for the original data). Whenever possible, the thermodynamic data that were defined up to $2000 \mathrm{~K}$ (below the highest temperatures investigated herein) were also changed for data covering a larger range of temperatures. These modifications however did not significantly change the predictions from the model of Zhou and coworkers.

To explain the other modifications adopted during this study, it is first necessary to look at the performances of the Zhou et al. model at predicting the water profiles in Fig. 3. As can be seen, the water profile is poorly predicted by this model for all conditions investigated: the water formation starts immediately, and the water concentration steadily increases to about $50 \%$ of its final value during what corresponds to $\tau_{\text {ign }}$. This early formation of water is also observed for all the other models based on Zhou et al. (Bongartz and Ghoniem [1], and, not shown for clarity purpose because the same behavior is exhibited, Mathieu et al. [3] and Mohammed et al. [9]). A reaction pathway analysis showed that the following reactions were chiefly responsible for this early formation of water (note that the reaction numbers hereafter correspond to the reaction number within the current model):

$$
\begin{array}{lll}
\mathrm{SH}+\mathrm{HO}_{2} \leftrightarrows \mathrm{H}_{2} \mathrm{~S}+\mathrm{O}_{2} & \mathrm{R} 62 & \text { (in reverse) } \\
\mathrm{H}_{2} \mathrm{O}_{2}+\mathrm{SH} \leftrightarrows \mathrm{H}_{2} \mathrm{~S}+\mathrm{HO}_{2} & \mathrm{R} 67 & \text { (in reverse) }
\end{array}
$$




$$
\begin{array}{ll}
\mathrm{H}_{2} \mathrm{O}_{2}(+\mathrm{M}) \leftrightarrows \mathrm{OH}+\mathrm{OH}(+\mathrm{M}) & \mathrm{R} 18 \\
\mathrm{H}_{2} \mathrm{~S}+\mathrm{OH} \leftrightarrows \mathrm{SH}+\mathrm{H}_{2} \mathrm{O} & \mathrm{R} 64
\end{array}
$$

The reactions R18 and, to a lesser extent, R64 have been much more studied than R62 and R67, both having been determined theoretically by Zhou and coworkers. Among these two reactions, R62 has the largest impact on the water profile, and it was not possible to obtain a satisfactory shape for the water profile by decreasing the rates of R62 and R67 within their claimed uncertainty (factor of 3). Interestingly, the model developed for carbonyl sulfide by Glarborg and Marshall [16] contains a $\mathrm{H}_{2} \mathrm{~S}$ sub-mechanism, and that model predicts with reasonable accuracy the water profiles measured experimentally, with a flat water profile before the ignition. This agreement with the data is made possible by the reaction rate they used for R62, where the reaction rate coefficient calculated by Montoya et al. [17] was used, but with a different value for the coefficient $n$ for the temperature $\left(\mathrm{k}_{62}=2.77 \times 10^{5} T^{2.76} \exp (-19,222 / T) \mathrm{cm}^{3} \mathrm{~mol}^{-1} \mathrm{~s}^{-1}\right.$ originally against $\mathrm{k}_{62}=2.77 \times 10^{5} T^{1.94} \exp (-19,222 / T) \mathrm{cm}^{3} \mathrm{~mol}^{-1} \mathrm{~s}^{-1}$ in Glarborg and Marshall [16]). This difference in $n$ induces a decrease in the rate for R62 by a factor well above 100 under the conditions of the present study. Note that R62 was also calculated by Zhou et al. [7] using multireference methods and that the two calculated values are close (factor $<3$ under the conditions of this study, which is within the claimed uncertainty for these two reactions (factor 3)).

The tentative model of the present study was therefore developed on the assumption that the reaction rate calculated for R62 in Zhou et al. is close to the real reaction rate, and R62 was therefore decreased as minimally as possible to obtain a flat water profile before the ignition. A decrease by a factor 10 was found necessary, and since this reaction has also a very important effect on the ignition delay time, it was then mandatory to modify other reaction rates (within their claimed uncertainty) to match the reactivity observed experimentally. 
The reactions for which their rates have been modified were selected based on sensitivity, reaction pathway, and rate of production analyses and with the new ignition delay times (overall reactivity of the model) and water profiles as targets. One can conclude from these modifications that the model proposed here can be viewed as a preliminary model only. All the modifications described below are based on the aforementioned estimate for R62, so these changes will probably need to be adjusted if a better value for the rate coefficient of R62 is obtained in the future. The reactions that have been modified in the $\mathrm{H}_{2} \mathrm{~S}$ sub-mechanism of Zhou et al. are listed in Table 1. In addition to these modified reactions, species and reactions that were present only in the model of Glarborg and Marshall were added to the tentative model. The model of the present study is comprised of 47 species and 308 reactions (44 species and 276 reactions for the model of Zhou et al.) and is available as supplementary material.

Table 1: Reactions from the model of Zhou et al. [7] modified during this study.

\begin{tabular}{|c|c|c|c|}
\hline Reaction & Comment & Reaction & Comment \\
\hline $\mathrm{R} 43: \mathrm{S}_{2}+\mathrm{H}+\mathrm{M} \leftrightarrows \mathrm{HSS}+\mathrm{M}$ & $\times 3$ & $\mathrm{R} 80: \mathrm{SH}+\mathrm{O} \leftrightarrows \mathrm{H}+\mathrm{SO}$ & $/ 3$ \\
\hline $\mathrm{R} 44: \mathrm{H}+\mathrm{HSS} \leftrightarrows 2 \mathrm{SH}$ & $/ 3$ & $\mathrm{R} 81: \mathrm{SH}+\mathrm{OH} \leftrightarrows \mathrm{S}+\mathrm{H}_{2} \mathrm{O}$ & $/ 1.4$ \\
\hline R46: $\mathrm{SH}+\mathrm{SH}(+\mathrm{M}) \leftrightarrows \mathrm{HSSH}(+\mathrm{M})$ & $\times 3$ & $\mathrm{R} 91: \mathrm{SH}+\mathrm{SO} \leftrightarrows \mathrm{S}_{2} \mathrm{O}+\mathrm{H}$ & $/ 3$ \\
\hline $\mathrm{R} 62: \mathrm{SH}+\mathrm{HO}_{2} \leftrightarrows \mathrm{H}_{2} \mathrm{~S}+\mathrm{O}_{2}$ & $/ 10$ & R106: $\mathrm{HSO}+\mathrm{O}_{2} \leftrightarrows \mathrm{HO}_{2}+\mathrm{SO}$ & $\times 2$ \\
\hline R64: $\mathrm{H}_{2} \mathrm{~S}+\mathrm{OH} \leftrightarrows \mathrm{SH}+\mathrm{H}_{2} \mathrm{O}$ & From [18] & R122: $\mathrm{HSO}+\mathrm{H} \leftrightarrows \mathrm{S}+\mathrm{H}_{2} \mathrm{O}$ & $\times 3$ \\
\hline R65: $\mathrm{H}_{2} \mathrm{~S}+\mathrm{O} \leftrightarrows \mathrm{SH}+\mathrm{OH}$ & From [19] & R180: $\mathrm{HOSO}(+\mathrm{M}) \leftrightarrows \mathrm{HSO}_{2}(+\mathrm{M})$ & $\times 2$ \\
\hline R66: $\mathrm{HSO}+\mathrm{H} \leftrightarrows \mathrm{H}_{2} \mathrm{~S}+\mathrm{O}$ & From $[20]$ & R204: $\mathrm{HOSO}+\mathrm{O}_{2} \leftrightarrows \mathrm{HO}_{2}+\mathrm{SO}_{2}$ & $/ 3$ \\
\hline
\end{tabular}




\begin{tabular}{|l|l|l|l|}
\hline $\mathrm{R} 67: \mathrm{H}_{2} \mathrm{O}_{2}+\mathrm{SH} \leftrightarrows \mathrm{H}_{2} \mathrm{~S}+\mathrm{HO}_{2}$ & $\times 1.5$ & $\mathrm{R} 207: \mathrm{HOSO}+\mathrm{H} \leftrightarrows \mathrm{SO}^{*}+\mathrm{H}_{2} \mathrm{O}$ & $\times 3$ \\
\hline $\mathrm{R} 75: \mathrm{SH}+\mathrm{O}_{2} \leftrightarrows \mathrm{HSO}+\mathrm{O}$ & $\times 3$ & $\mathrm{R} 223: \mathrm{S}_{2}+\mathrm{O} \leftrightarrows \mathrm{SO}+\mathrm{S}$ & $/ 1.5$ \\
& & & \\
\hline
\end{tabular}

The ignition delay time predictions for the tentative model as well as for the models from the literature are visible in Fig. 2 (b-d), for $\phi=0.5,1.0$, and 1.5, respectively. As can be seen, the ignition delay times measured during this study are well predicted (within 10\%) by the model (the model being slightly over-reactive at $\phi=0.5$ and slightly under-reactive at $\phi=1.5)$. In comparison, the model of Zhou et al. [7] and all models based on their work (Bongartz and Ghoniem [1], Mathieu et al. [3], Mohammed et al. [9]) present an activation energy that is too high, while the discrepancies with the experimental data vary with the modifications adopted by each group (the model of Bongartz and Ghoniem being the closest to the data with fair accuracy for most of the conditions).

Interestingly, the model of Mathieu et al. [3] and the model of Bongartz and Ghoniem optimized to shock-tube, flame speed, and flow reactor data at pyrolysis conditions (“Optimization 1-7”) are yielding similar results, where $\tau_{\mathrm{ign}}$ are severely over-predicted at low temperature. Their model optimized for all data available, including $\mathrm{H}_{2} \mathrm{~S}$ oxidation in flow reactor (“Optimization 1-12") is closer to the new set of data but is also not in very good agreement with the former experimental data of Mathieu et al. [3]. This behavior illustrates the current difficulty in reconciling results for the oxidation of $\mathrm{H}_{2} \mathrm{~S}$ in both shock tubes and flow reactors. However, it is important to note that the new $\tau_{\text {ign }}$ presented herein are more accurately predicted by the models that have been validated using the flow reactor data of Zhou et al. [7], than by models focusing primarily on other results. Therefore, these new ignition delay time results seem to indicate that shock-tube 
and flow reactor data could possibly be reconciled, provided that the right key reaction rates are properly adjusted.

Despite the very large difference in the reaction rate of R62, it is interesting to see that the model of Glarborg and Marshall predicts ignition delay time with high accuracy for temperatures below $2000 \mathrm{~K}$. Above this temperature, the predicted $\tau_{\mathrm{ign}}$ are too long. These good overall predictions were possible due to the rate they used for $\mathrm{R} 75\left(\mathrm{SH}+\mathrm{O}_{2} \leftrightarrows \mathrm{HSO}+\mathrm{O}\right)$, which is more than 10 times faster than the rate calculated by Zhou and coworkers. Note that the rates for many reactions are similar (or without importance under the condition of the present study) between the models of Zhou et al. and Glarborg and Marshall.

As discussed above, the water profile is poorly predicted by the model of Zhou et al. and its derivative models. The model of Glarborg and Marshall, on the other hand, predicts the new profiles with fair accuracy (Fig. 3). Notably, the time at which water concentration starts increasing is well predicted at all conditions investigated. However, note that no water profiles were measured above $2000 \mathrm{~K}$, where the model of Glarborg and Marshall is less accurate. Nevertheless, some discrepancies can be observed, such as the beginning of the water formation that is too abrupt at $\phi=1.0$ and 1.5. Also, the formation of water seems to be too high after the inflexion point of the water profile and before the plateau is reached. This overestimate is also the case for the tentative model of the present study, which predicts the water profiles with fair accuracy. The tentative model's water formation tends to start slightly too early at $\phi=0.5$ and slightly too late at fuel rich conditions (Fig. 3), in agreement with the ignition delay time predictions (Fig. 2). However, the shape of the water profile is a better predicted overall, notably at the beginning of the increase in the water concentration at $\phi=1.0$ and 1.5 and for the peak right after the growth period at $\phi=1.5$. 
To exhibit the differences between the current model and the original model from Zhou et al., a sensitivity analysis was conducted on $\mathrm{OH}^{*}$ (representative of the chemistry involved in the ignition delay time) and the results for the case at $\phi=1,1 \mathrm{~atm}$, intermediate temperature (1780 $\mathrm{K})$, are visible in Fig. 4. As can be seen, the 3 most-promoting reactions and the single mostinhibiting reaction are the same for these two mechanisms, indicating that the $\mathrm{H}_{2} \mathrm{~S}$ chemistry with regards to $\mathrm{OH}^{*}$ was not too severely altered by the modifications adopted within the tentative model. Among the noticeable differences, one can mention that $\mathrm{R} 75\left(\mathrm{SH}+\mathrm{O}_{2} \leftrightarrows \mathrm{HSO}+\mathrm{O}\right)$ and $\mathrm{H}_{2} \mathrm{~S}+\mathrm{H} \leftrightarrows \mathrm{SH}+\mathrm{H}_{2}$, which are among the 10 most-sensitive reactions for the tentative model and Zhou et al.'s mechanism only, respectively, each with a large sensitivity coefficient. Note that the importance of R75 was underlined for both the model of Glarborg and Marshall and the current model, as discussed above. A better estimate for this reaction would therefore be helpful. Finally, one can notice that all the inhibiting reactions are pyrolytic reactions for $\mathrm{H}_{2} \mathrm{~S}$. Hence, more data under pyrolysis conditions would also be necessary to fully validate this sub-mechanism and improve the overall $\mathrm{H}_{2} \mathrm{~S}$ chemistry. Equivalent results and conclusions can be obtained when $\mathrm{H}_{2} \mathrm{O}$ is selected as the target.

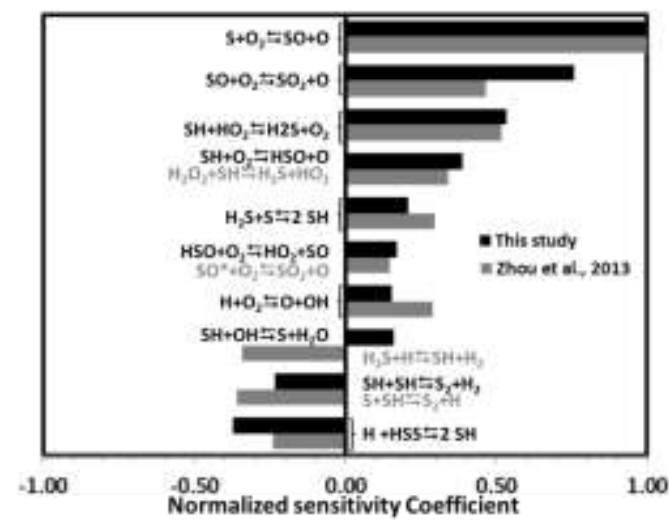

Figure 4: Normalized $\mathrm{OH}^{*}$ sensitivity analysis for the tentative model and the model of Zhou et al. [7]. Conditions: $0.008 \mathrm{H}_{2} \mathrm{~S} / 0.012 \mathrm{O}_{2} / 0.98 \mathrm{Ar}, 1780 \mathrm{~K}, 1 \mathrm{~atm}$. 
The ignition delay time data for a $\mathrm{H}_{2} / \mathrm{O}_{2}$ mixture seeded with $1600 \mathrm{ppm}$ of $\mathrm{H}_{2} \mathrm{~S}$ at various pressures from Mathieu et al. [3] were also modeled using the present model and the original model of Zhou and coworkers. As can be seen in Fig. 5, the updated model predictions are better than those of the original model, especially at higher pressure, where the tentative model is closer (12.6 atm) or follows the experimental trend (33.5 atm). At the highest pressure investigated, the tentative model under-predicts $\tau_{\text {ign }}$ within a factor of 2. As in Mathieu et al. [3], a sensitivity analysis shows the importance of $\mathrm{R} 46(\mathrm{SH}+\mathrm{SH}(+\mathrm{M}) \leftrightarrows \mathrm{HSSH}(+\mathrm{M}))$ at high pressure, and a better estimate of this reaction seems necessary for high-pressure experiments in shock tubes.

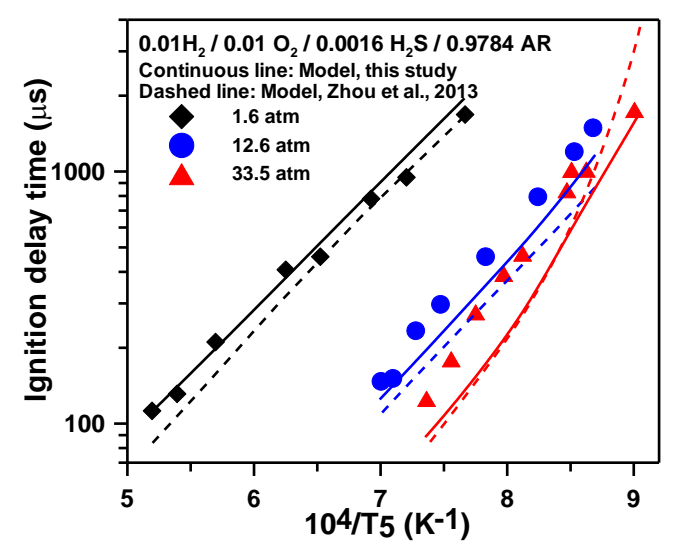

Figure 5: Ignition delay times for a $\mathrm{H}_{2} / \mathrm{O}_{2} / \mathrm{H}_{2} \mathrm{~S}$ mixture in $\mathrm{Ar}$ at various pressures in comparison with predictions, from Mathieu et al. [3].

\section{Conclusion}

New ignition delay times and laser-absorption water profiles were measured in two different shock tubes at atmospheric pressure. The comparison between the experimental and predicted water profiles highlighted important flaws in the original model of Zhou and coworkers and all 
derivative models. It was not possible to correct these flaws by adjusting reaction rates within their uncertainty, but it was possible to obtain both good water profile and $\tau_{\text {ign }}$ predictions by decreasing the rate of $\mathrm{R} 62\left(\mathrm{SH}+\mathrm{HO}_{2} \leftrightarrows \mathrm{H}_{2} \mathrm{~S}+\mathrm{O}_{2}\right)$ by a factor of 10 and by adjusting the rates of some other reactions within their uncertainties. The new $\tau_{\text {ign }}$ data are in much better agreement with models that were validated with flow reactor data compared to models validated without them, indicating that shock-tube and flow reactor data could potentially be reconciled in the future. Predictions for higher-pressure data were also improved compared to the original model, although there is still room for improvements and there continues to be a need for more data in this area. As noticed in former studies, many important reactions are very sensitive during $\mathrm{H}_{2} \mathrm{~S}$ combustion. The present study shows that more accurate rates for at least the reactions R62 $\left(\mathrm{SH}+\mathrm{HO}_{2} \leftrightarrows \mathrm{H}_{2} \mathrm{~S}+\mathrm{O}_{2}\right), \mathrm{R} 75\left(\mathrm{SH}+\mathrm{O}_{2} \leftrightarrows \mathrm{HSO}+\mathrm{O}\right)$, and $\mathrm{R} 46(\mathrm{SH}+\mathrm{SH}(+\mathrm{M}) \leftrightarrows \mathrm{HSSH}(+\mathrm{M}))$ would be needed. New experimental data, notably for $\mathrm{H}_{2} \mathrm{~S}$ pyrolysis, would also be helpful to further validate the model.

6. Acknowledgments:

This material is based upon the work supported by the Department of Energy under Award Number DE-FE0011778 and by the National Science Foundation under Award Number 2014156577.

\section{References}

[1] D. Bongartz, A. F. Ghoniem. Combustion and Flame 162 (2015) 544-553. 
[2] O. Mathieu, J. Hargis, A. Camou, C. Mulvihill, E. L. Petersen. Proceed. Combust. Institute 35 (2015) 3143-3150.

[3] O. Mathieu, F. Deguillaume, E. L. Petersen. Combustion Flame 161 (2014) 23-36.

[4] O. Mathieu, J. W. Hargis, E. L. Petersen, J. Bugler, H. J. Curran, F. Güthe. Paper GT 201425412, Proceedings of ASME Turbo Expo 2014, June 16-20, 2014, Düsseldorf, Germany.

[5] F. G. Cerru, A. Kronenburg, R. P. Lindstedt, Combust. Flame 146 (2006) 437-455.

[6] H. Selim, A. Al Shoaibi, A. K. Gupta. Applied Energy 88 (2011) 2601-2611.

[7] C. R. Zhou, K. Sendt, B. S. Haynes, Proc. Combust. Inst. 34 (2013) 625-632.

[8] D. Bongartz, A. F. Ghoniem. Combustion and Flame 162 (2015) 2749-2757.

[9] S. Mohammed, A. Raj, A. Al Shoaibi, P. Sivashanmugam. Chemical Engineering Science 137 (2015) 91-105.

[10] E. L. Petersen, M. J. A. Rickard, M. W. Crofton, E. D. Abbey, M. J. Traum, D. M. Kalitan. Meas. Sci. Technol. 16 (2005) 1716-1729.

[11] L. S. Rothman. The HITRAN molecular spectroscopic database and HAWKS (HITRAN Atmospheric Workstation): 1996 edition. Journal of Quantitative Spectroscopy \& Radiative Transfer 60 (1998) 665-710.

[12] E. E. Whiting. Journal of Quantitative Spectroscopy \& Radiative Transfer 8 (1968) 13791384.

[13] A. Kéromnès, W. K. Metcalfe, K. A. Heufer, N. Donohoe, A. K. Das, C.-J. Sung, J. Herzler, C. Naumann, P. Griebel, O. Mathieu, M. C. Krejci, E. L. Petersen, W. J. Pitz, H. J. Curran. Combustion and Flame 160 (2013) 995-1011. 
[14] J. M. Hall, E. L. Petersen. Int. J. Chem. Kinet. 38 (2006) 714-724.

[15] E. Goos, A. Burcat, B. Ruscic. Ideal gas thermochemical database with updates from active thermochemical tables, 2013. <http://garfield.chem.elte.hu/Burcat/burcat.html>.

[16] P. Glarborg, P. Marshall. Int J. Chem. Kinet. 45 (2013) 429-439.

[17] A. Montoya, K. Sendt, B. S. Haynes. J. Phys. Chem. A 109 (2005) 1057-1062.

[18] G. S.Tyndall, A. R. Ravishankara. Int. J. Chem. Kinet. 23 (1991) 483-527.

[19] A. Goumri, D. Laakso, J.-D. R. Rocha, C. E. Smith, P. Marshall. J. Chem. Phys. 102 (1995) 161-169.

[20] P. Glarborg, D. Kubel, K. D.-Johansen, H.-M. Chiang, J. W. Bozzelli. Int. J. Chem. Kinet. 28 (1996) 773-790. 


\section{List of Tables and Figures}

Table 1: Reactions from the model of Zhou et al. [7] modified during this study.

Figure 1: Schematic of the laser diagnostic used during this study.

Figure 2: Ignition delay time measurements for $\mathrm{H}_{2} \mathrm{~S} / \mathrm{O}_{2}$ mixtures in $98 \% \mathrm{Ar}$ (a) and comparison with models at $\phi=0.5$ (b), $\phi=1.0$ (c), and $\phi=1.5$ (d).

Figure 3: Evolution with equivalence ratio and temperature of water time-histories during the oxidation of $\mathrm{H}_{2} \mathrm{~S} / \mathrm{O}_{2}$ mixtures in $98 \%$ Ar.

Figure 4: Normalized $\mathrm{OH}^{*}$ sensitivity analysis for the tentative model and the model of Zhou et al. [7]. Conditions: $0.008 \mathrm{H}_{2} \mathrm{~S} / 0.012 \mathrm{O}_{2} / 0.98 \mathrm{Ar}, 1780 \mathrm{~K}, 1 \mathrm{~atm}$.

Figure 5: Ignition delay times for a $\mathrm{H}_{2} / \mathrm{O}_{2} / \mathrm{H}_{2} \mathrm{~S}$ mixture in $\mathrm{Ar}$ at various pressures in comparison with predictions, from Mathieu et al. [3]. 


\section{List of supplementary material}

Table S1: Details on the mixtures investigated near atmospheric pressure.

Table S2: Ignition delay times and associated conditions behind reflected shock waves

Figure S1: Determination method of the ignition delay time used during this study.

Figure S2: Comparison between experiments and computed results with the tentative model for normalized $\mathrm{OH}^{*}$ profiles at $\phi=0.5$.

Figure S3: Comparison between experiments and computed results with the tentative model for normalized $\mathrm{OH}^{*}$ profiles at $\phi=1$.

Figure S4: Comparison between experiments and computed results with the tentative model for normalized $\mathrm{OH}^{*}$ profiles at $\phi=1.5$.

Figure S5: Comparison between experiments and computed results with the tentative model for water profiles at $\phi=0.5$.

Figure S6: Comparison between experiments and computed results with the tentative model for water profiles at $\phi=1.0$.

Figure S7: Comparison between experiments and computed results with the tentative model for water profiles at $\phi=1.5$.

Detailed kinetics mechanism 